\title{
Decompressive craniectomy in the management of traumatic brain injury: a review of current practice
}

This article was published in the following Dove Press journal:

Open Access Surgery

20 October 2015

Number of times this article has been viewed

\section{Wilfred Chukwuemeka \\ Mezue \\ Chika Anele Ndubuisi ${ }^{2}$ \\ 'Department of Surgery, Neurosurgery Unit, University of Nigeria Teaching Hospital, ${ }^{2}$ Memfys Hospital for Neurosurgery, Enugu, Nigeria}

\begin{abstract}
Decompressive craniectomy (DC) is now well established in the management of intractable raised intracranial pressure from various indications including trauma, ischemic strokes, and postoperative tumor surgery. In the setting of traumatic brain injury, the procedure has remained controversial - a difficulty that has not been completely resolved by available randomized studies. Available evidence suggests that there is a need for more clarity in the indications for DC in trauma, the intracranial pressure thresholds, and the timing of intervention. There is also a need to carefully distinguish between primary and secondary DC and to distinguish both from decompressive craniotomy if we are to resolve the current controversy. This article reviews the place and utility of DC in traumatic brain injury and the complications of the condition.
\end{abstract}

Keywords: craniectomy, decompression, traumatic brain injury

\section{Introduction}

Decompressive craniectomy (DC) has had a long and checkered history. While many studies have demonstrated the effectiveness of DC in reducing intracranial pressure (ICP) and improving mortality from severe traumatic brain injury (TBI), others have questioned its overall usefulness. The major difficulty was the discrepancy between survival and the quality of that survival. Outcomes measuring survival encouraged the use of DC, while outcomes measuring quality of survival questioned the utility of DC. This mixed outcome made the procedure somewhat unpopular among neurosurgeons. Advances in neurointensive care and neuroimaging, however, led to a resurgence of interest and made it possible to review the clinical indications and the very definition of DC. The clear advantages documented for DC in nontraumatic cases provided additional support for the argument in favor of DC in TBI. ${ }^{1-3}$

Although quality of life remained a significant issue, studies suggested that the careful selection of patients may result in overall better outcomes. ${ }^{4-7}$ It has been well established that the clinical state of the patient at the point of intervention influenced outcomes. Specific factors include the Glasgow Coma Score (GCS) after full resuscitation, pupillary size and reaction, age, ICP, imaging findings, timing and extent of surgery in terms of technique, and size of the bone flap. ${ }^{4-8}$ Series that exclude patients with bilaterally dilated pupils, age above 65 years, and a GCS below 5 consistently reported better outcomes. ${ }^{4,6,7}$ At what point in the patient's illness a decision for DC should be made must therefore be clarified in order to properly evaluate the outcome of DC in TBI.

ICP management offered a logical, reproducible, systematic approach to the management of severe TBI. Although there is no class 1 evidence supporting its use, there is sufficient level 2 and level 3 evidence for ICP monitoring in the management of severe
Correspondence: Wilfred Chukwuemeka Mezue

Department of Surgery, University

of Nigeria Teaching Hospital, PO Box 0I I29, Enugu, Nigeria Email mezuec@hotmail.com 
head injury. The Brain Trauma Foundation (BTF) guidelines recommend ICP monitoring in all salvageable patients with severe TBI and an abnormal computed tomography (CT) scan. While not a recommendation, the BTF guidelines suggest that ICP monitoring is indicated in severe TBI patients with normal CT if two or more of the following factors are present on admission: age $>40$ years; unilateral or bilateral motor posturing; or systolic blood pressure $<90 \mathrm{mmHg} .^{8-10}$ $\mathrm{ICP} /$ cerebral perfusion pressure (CPP)-driven protocols became the basis for the management of severe TBI in most centers. ${ }^{11}$ Increasing use of ICP monitoring offered the hope of providing measurable criteria for the selection of patients for DC, ${ }^{12,13}$ and randomized studies were set up to properly weigh the role of DC in TBI. Unfortunately, the threshold for ICP that should be used for such trials remained controversial, and the two major trials (DECRA and RESCUEicp) used 20 $\mathrm{mmHg}$ and $25 \mathrm{mmHg}$, respectively. ${ }^{14,15}$

However, while not denying the value of ICP/CPP protocols, their role in the management of severe TBI is not generally agreed upon. Chesnut et al, ${ }^{9}$ in a randomized trial, showed that care based on ICP protocols is not superior to that based on imaging and clinical criteria. In centers worldwide, where for reasons of lack of ICP monitoring, the use of $\mathrm{DC}$ in TBI is based on neuroradiological and clinical criteria alone; the results of DC after optimized medical treatment, including ICP-lowering therapies, did not differ greatly from those where ICP and maximal medical treatment are the necessary basis for surgical intervention. ${ }^{9}$ In addition, measuring the ICP threshold was not an overwhelming consideration when deciding on an intervention with DC in patients suffering from large middle cerebral artery (MCA) infarcts where neuroradiological and clinical criteria were routinely used.

As pointed out by Haddad and Arabi, ${ }^{16}$ the potential benefits of ICP monitoring, including the earlier detection of an intracranial mass lesion, guidance of therapy, and avoidance of the indiscriminate use of therapies to control ICP, drainage of cerebrospinal fluid (CSF) with a reduction in the ICP and improvement of the CPP, have a sound physiological basis. DC is primarily targeted at reducing ICP and represents one of many modalities for such control. The outcome of DC and at what point it should be considered, however, remain to be resolved. The multimodal intensive care management of patients with TBI involves expanding the care available for these patients, and it has become increasingly apparent that management targeted at raised ICP alone is inadequate.

The outcomes for DC should be assessed against a background of optimized medical treatment that includes ensuring optimal perfusion and oxygenation. Maximal medical treatment, as is currently used, implies that medical therapy is no longer effective in the control of refractory raised ICP. Unless defined rigorously in terms of how long it should be pursued, such maximal medical treatment harbors the potential of increased brain injury. ${ }^{17} \mathrm{DC}$ done on this basis may prove ineffective without reflecting entirely on the procedure. Unfortunately, no studies are available to determine this duration, and randomized studies on DC have used different criteria for the duration of raised ICP before the intervention (15 minutes in DECRA, and 1 hour for RESCUEicp). ${ }^{14,15}$ It is, of course, unarguable that resuscitation and medical optimization are essential in the management of the head injured patient along the lines of the established guidelines. However, until a clear guideline for DC becomes available, it is essential to consider earlier interventions with DC in TBI following optimal medical treatment, defined as optimized physiological parameters (pulse, blood pressure, urine output, and biochemical balance) in a severely head injured patient with clinicoradiological evidence of raised ICP or a measured ICP of not $>25 \mathrm{mmHg}$.

When making decisions for de compressive surgery, the extent of surgical decompression must be planned from the beginning. There is a need to distinguish between DC and decompressive craniotomy. While DC is essential for the patient with intractable raised ICP, a more limited surgery where the bone is not reattached, but allowed to float, may be appropriate for patients with increased ICP from recognizable and treatable associated surgical lesions. The definition of decompressive surgery in these circumstances thus needs to be more rigorous, as does the definition of clinical and radiological criteria, which is acceptable as an indication for intervention. DC and craniotomy have been confounded in many individual series, increasing the difficulties of defining the efficacy of DC in severe TBI. These issues form the basis for this review.

\section{Brief historical perspective}

The practice of trepanation dates back to 10,000 BC, around the early Neolithic period. The archeological evidence of this practice has been documented in all continents of the world. Between 460 BC and 370 BC, Hippocrates documented that visual loss, presumably resulting from elevated ICP, could be treated with trepanation. ${ }^{18}$

With better understanding of neuroanatomy during the Renaissance period, advances led to the modern era of trepanation. Theodor Kocher's assertion in 1901 that if there is no CSF pressure but brain pressure exists, then the pressure must be relieved by opening the skull captures the 
opinion at the time. ${ }^{19}$ Harvey Cushing in 1908 presented a case series demonstrating a reduction in the mortality rates of head injured patients from as high as $50 \%$ to $15 \%$ following treatment using subtemporal DC, ${ }^{20}$ which strengthened the role of DC in the management of brain edema after severe head injuries. During the second-half of the 20th century, wide variations and modifications in the options for DC, such as hemicraniectomy and bifrontal DC, became popularized, paralleled by marked individual variations in the observed outcome among the patients treated. In their studies, Lewin et $\mathrm{al}^{21}$ and Moody et al, ${ }^{22}$ however, noted very high mortality rates following DC and discouraged the use of DC. The resurgence of interest in DC followed the work of Guerra et al, ${ }^{23}$ who showed good results from his series of patients managed using CT and ICP monitoring. This introduced the era of ICP-driven protocols and the use of DC as the second-tier management for intractable ICP. ${ }^{23}$ These results from the late 20th century suggesting improvements in mortality following DC, when indicated, as compared to medical management alone, often raised concerns about the quality of life among survivors.

Earlier, Wilberger et $\mathrm{al}^{24}$ had identified raised ICP as the most important factor in predicting outcomes following severe TBI. It slowly emerged that while DC effectively controlled ICP, this did not translate into good outcomes. However, most of the studies were retrospective with small patient populations of variable composition in terms of age and management criteria. Therefore, since the beginning of the 21 st century, this lack of consensus has been a major issue, and randomized studies to properly weigh the role of DC in patient management became a focus of research in the field. A Cochrane Collaboration review in $2006^{25}$ identified only one randomized study in children. ${ }^{26}$ The overall conclusion from the review involving nonrandomized retrospective and prospective studies suggested the benefit for DC in TBI, but it did not find conclusive evidence to support the routine use of DC. Other randomized studies have since been mounted, and the result of the DECRA study was released in 2011. ${ }^{14}$

The more limited decompressive craniotomy was introduced in 1966 by Miyazaki, and subsequently popularized by Kjellberg and Prieto in $1971 .^{27}$

\section{Epidemiology}

Trauma is the leading cause of morbidity and mortality in all populations worldwide. The burden of trauma is highest in the third and fourth decades of life as a result of exposure to various predisposing risk factors, and this has a significant economic effect. In the adult population, and even among the pediatric age groups, TBI accounts for as high as $60 \%-80 \%$ of all trauma cases.$^{28}$ The true incidence of severe TBI is difficult to evaluate, even in developed countries. In North America, it is estimated that about 500/100,000 TBI cases of different severity are managed annually, with an annual estimated economic burden amounting to over US\$60 billion. ${ }^{28,29}$ In Australia, about 1,000 cases of TBI are diagnosed annually among the country's population of 22 million, with the lifetime cost estimated at $\$ 1$ billion. ${ }^{30}$ In Europe, an estimated 8,000 patients die annually from trauma, and in the United States, as high as 3\% of the cases of TBI die annually. ${ }^{30}$ From the available statistics, the burden of TBI in developing countries appears to be rapidly increasing. It is estimated that one out of every 200 families will be a victim of TBI in the developing countries, and these are countries with a limited budget to properly take care of highly specialized health care services. ${ }^{31}$ TBI should therefore be viewed as an emerging epidemic, or at least a major public health issue in developing countries.

\section{Raised ICP/physiology of DC}

Accepted normal values of ICP vary with age. The normal values of ICP range from subatmospheric in the newborn to about $10-15 \mathrm{mmHg}$ in the average adult..$^{32}$ The limits of welltolerated ICP varies from 18-20 mmHg in subarachnoid hemorrhage, 20-22 mmHg in malignant MCA stroke, $25 \mathrm{mmHg}$ in trauma, and $30-40 \mathrm{mmHg}$ in slow-growing tumors and hydrocephalus. ${ }^{32}$ In TBI, increased ICP is usually diagnosed when the ICP rises above values of $20-25 \mathrm{mmHg}$, and rising values is a reflection of the severity of the TBI and the need for more aggressive treatment. These include a range of medical and supportive treatments, and when ICP proves refractory in spite of these, DC becomes an option.

DC negates the Monro-Kellie hypothesis of fixed intracranial volume and relieves pressure permanently by allowing the brain to herniate through the defect created. ${ }^{11}$ Reducing ICP will help to maintain an adequate cerebral blood flow $(\mathrm{CBF})$ and $\mathrm{CPP}(\mathrm{CPP}=\mathrm{MAP}-\mathrm{ICP})$.

This external expansion will also relieve the progressive effect of internal brain herniation. Schwab et $\mathrm{al}^{32}$ calculate that a craniectomy of $8 \mathrm{~cm}$ will give only a supplemented volume of $23 \mathrm{~mL}$, approximately $1.5 \%$ of brain volume, while a $12 \mathrm{~cm}$ diameter will provide volume supplementation of $86 \mathrm{~mL}$. To achieve adequate decompression, craniectomy should therefore be at least $10 \mathrm{~cm}$ in diameter. ${ }^{33} \mathrm{DC}$ significantly lowers ICP more so than barbiturate coma and hypothermia, but as shown from the DECRA study, it does not commensurately improve outcome. ${ }^{14}$ 
Autoregulation allows for constant blood flow in response to fluctuations in mean arterial pressure (MAP). When MAP falls below $60 \mathrm{mmHg}$ or exceeds $150 \mathrm{mmHg}$, autoregulation fails to maintain CBF. Since cerebral metabolism is linked to blood flow, a decrease in $\mathrm{CBF}$ represents a serious threat to the damaged brain, especially as other concurrent mechanisms such as seizures demand increased metabolic activity and increased blood flow. If ICP is not controlled, ICP rises to the point where it equals MAP, and this cuts off blood flow to the brain and parallels the onset of coning. Targeted studies in the last few decades have determined that the management of severe TBI should be based on ICP and CPP values. ${ }^{34-37}$

However, the practice of ICP monitoring has its own difficulties and controversies. While many studies suggest that ICP monitoring reduces mortality in severe TBI, ${ }^{38-41}$ this is not generally accepted, ${ }^{42-44}$ and indeed a few studies have suggested that ICP monitoring actually worsens the outcome. ${ }^{45,46}$ Haddad et $\mathrm{al}^{47}$ showed that ICP monitoring increases the time on ventilation and the rate of tracheostomies. There is a linear association between the odds ratio of death and the degree of elevation of ICP. An ICP of 20-40 $\mathrm{mmHg}$ has an odds ratio of death of 3.5, while with an ICP above $40 \mathrm{mmHg}$ rises to 6.9. When raised ICP is refractory, the odds ratio of death has been shown to be as high as 114.3 , and even when reducible, there is a $3-4$-fold increase in the odds ratio of death or disability. ${ }^{16,48}$

The acceptable period that sustained high ICP can run before intervention also contributes to the overall outcome. The threshold for the diagnosis of malignant intracranial hypertension ( $\mathrm{IH}$ ) has not been reliably defined, and thus the threshold for initiating treatment is not consistent. There is sufficient evidence to suggest that values of ICP between $20 \mathrm{mmHg}$ and $25 \mathrm{mmHg}$, and values of CPP below $50-55 \mathrm{mmHg}$, are associated with higher mortality in patients with TBI, ${ }^{12,13,49,50}$ and such patients may benefit from DC. Values above $30-40 \mathrm{mmHg}$ may suggest malignant IH. These facts may, in the end, prove definitive for the results of the DECRA (ICP threshold: $20 \mathrm{mmHg})^{14}$ and RESCUEicp (threshold: $25 \mathrm{mmHg})^{15}$ studies.

The DECRA study showed a significant decrease in ICP in patients who had DC, in keeping with the Monro-Kellie doctrine. However, clinical outcomes assessed using the Extended Glasgow Outcome Scale were found to be worse in the surgical group than in the standard care group. The study has been questioned on many grounds. The most persistent criticism is that raised ICP was considered in the study to be refractory when sustained above $20 \mathrm{mmHg}$ for more than 15 minutes within a 1-hour period after maximal medical interventions. ${ }^{51}$ Simard et $\mathrm{al}^{52}$ point out that such early surgical intervention would not allow sufficient time for an optimized medical intervention. There is evidence that the outcome of a head injury is determined by ICP thresholds of $25 \mathrm{mmHg},{ }^{13}$ and thus that patients with an ICP above $25 \mathrm{mmHg}$ are more likely to benefit from decompression. ${ }^{53}$

While the threshold for operations in the DECRA study may be low, a threshold ICP set just above normal anticipates the damage to neural structures when higher thresholds for longer periods are used, and such early DC may provide the best opportunity to study the impact of DC on improving outcomes. It has been well established that the control of ICP and normalization of CPP do not translate into good outcomes for TBI. ${ }^{54,55}$ Medical modalities targeting ICP, such as hypothermia, hyperventilation, and the removal of CSF and barbiturate use, have all been shown to effectively reduce ICP without improving outcomes. ${ }^{54,55}$ Possible explanations for this include persisting cerebral hypoxia ${ }^{56,57}$ and inadequate perfusion. Inadequate perfusion in the presence of normalized ICP was demonstrated by Coles et $\mathrm{al}^{58}$ in patients treated with severe hyperventilation. The result of the DECRA study, therefore, may be a confirmation that the normalization of ICP is not the primary issue in the management of patients with TBI, ${ }^{59}$ and that more weight should be given to multimodality monitoring in the care of these patients.

The exclusion of patients with mass lesions from the DECRA study has also been challenged, but it actually adds to the strength of the study. Strictly defined DC for TBI should exclude conditions where surgery is needed for the underlying condition. Such a rigorous definition avoids the confounding effect of the tardy management of traumatic intracranial lesions with that of the management of intractable ICP from severe TBI. In addition, such patients may not need classical DC, and its use may result in reports of favorable outcomes that are not reproducible when the criteria are better defined. The technique of decompressive craniotomy, where the bone is left in situ but allowed to float, has been used effectively in many of these cases, ${ }^{60}$ to an extent that randomized studies of classical DC versus craniotomy in trauma patients is desirable.

It has also been pointed out that in spite of randomization, there were more patients with bilateral dilated pupils in the surgical group, and this may have contributed to the poor outcomes in the group. A second ongoing randomized study, the RESCUEicp study, randomly assigned patients to either DC or to standard care (including the use of barbiturates). ${ }^{15}$ The threshold ICP was $25 \mathrm{mmHg}$ for more than 1-12 hours at any time after injury, when maximal medical therapy fails 
to control the ICP. This study should significantly contribute to the question of the efficacy and timing of DC in TBI. The higher threshold of ICP used and the widened scope of decompressive techniques are within the scope of many surgeons' practice. It is important, however, to carefully distinguish the subgroup with a recognizable traumatic mass lesion.

The size of the craniectomy also affects the extent of ICP reduction $^{8}$ and the outcome of the procedure, as herniation through a tight ring of bone may result in venous obstruction and infarction. When properly performed, DC has been shown to decrease the therapeutic intensity level and cumulative ischemic burden of the brain. ${ }^{61}$

\section{Surgery for DC}

The available evidence shows that DC is effective in reducing ICP, ${ }^{40,62}$ but the outcome in terms of morbidity remains to be resolved. ${ }^{14,63,64} \mathrm{DC}$ is considered primary when the bone flap is removed after evacuation of a mass lesion in the acute phase. ${ }^{11,65,66}$ When DC is used as part of therapeutic protocols for IH secondary to diffuse brain injury and brain edema, the procedure is termed secondary or protocol-driven DC. ${ }^{11}$ Although the commonest indication for primary DC is acute subdural hematoma, ${ }^{67,68}$ many surgeons now primarily use DC for TBI where clinical and radiological features suggest the need to avoid postoperative worsening due to raised ICP. These patients traditionally were treated with craniotomy, and although DC has been shown to be more effective in noncontrolled studies, ${ }^{69}$ proper randomized trials are necessary to evaluate the role of DC in these settings. ${ }^{70}$

Decompressive craniotomy avoids many of the problems of DC, particularly the exposure to fluctuations of atmospheric pressure and the need for subsequent cranioplasty. While it can never provide the space that DC does, it not only modifies the Monro-Kellie equation, but it also often provides significant volume for brain expansion (Figures 1 and 2). The American Association of Neurological Surgeons (AANS) recommended decompressive craniotomy for TBI and refractory IH if patients meet some of the following criteria: 1) diffuse cerebral swelling on cranial CT imaging; 2) surgery within 48 hours of injury; 3) no episodes of sustained IH (ICP) $>40 \mathrm{mmHg}$ before surgery; 4 ) a GCS $>3$ at some point subsequent to injury; 5) secondary clinical deterioration; and 6) evolving cerebral herniation syndrome. ${ }^{71}$

DC undertaken as a last-tier therapy when a patient's IH is sustained at $20-35 \mathrm{mmHg}$ and refractory to medical treatment has been defined as secondary. ${ }^{11}$ This protocol-driven DC can also be performed earlier, ${ }^{63}$ but it must be distinguished from

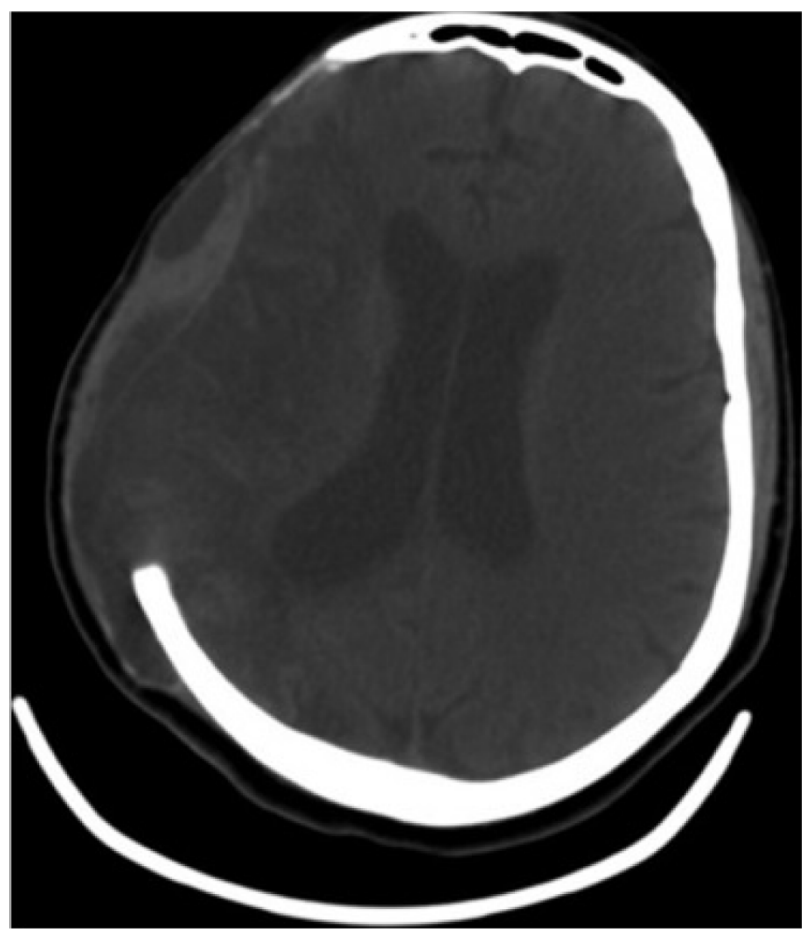

Figure I Right fronto-temporal decompressive craniectomy (DC).

Note: Copyright (C) 2013. Nigerian Journal of Clinical Practice. Reproduced from Mezue WC, Ndubuisi C, Ohaegbulam SC, Chikani M, Erechukwu U. Cranial bony decompressions in the management of head injuries: decompressive craniotomy or craniectomy? Niger J Clin Pract. 2013;16(3):343-347. ${ }^{17}$

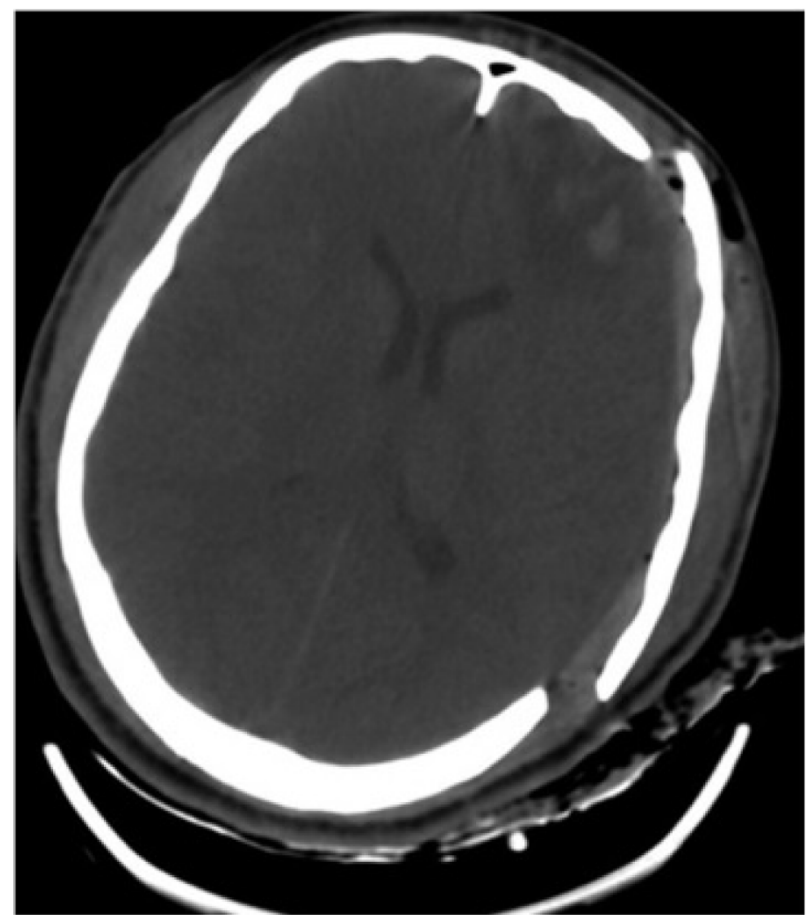

Figure 2 Left fronto-temporal decompressive craniotomy.

Note: Copyright (c) 2013. Nigerian Journal of Clinical Practice. Reproduced from Mezue WC, Ndubuisi C, Ohaegbulam SC, Chikani M, Erechukwu U. Cranial bony decompressions in the management of head injuries: decompressive craniotomy or craniectomy? Niger J Clin Pract. 2013;16(3):343-347. ${ }^{17}$ 
primary DC or craniotomy, as they apply to a different group of patients. Secondary DC also has a clearer definition and is the subject of ongoing randomized studies. ${ }^{15}$ Unfortunately, extrapolating the results of secondary DC to primary DC may be problematic. It is necessary to strictly define these two if we are to remain objective in analyzing the outcomes both in terms of morbidity and mortality. A lack of this definition is one of the reasons why DC as a surgical treatment has remained controversial. DCs done as a last resort should be analyzed for what they are: procedures aimed at survival and to control ICP. The quality of that survival will only come into consideration when the thresholds for ICP, time to surgery, and other factors affecting functional outcomes such as pupils, age, comorbidities, and GCS, are properly controlled. These will hopefully become clearer as randomized clinical trials become available.

Primary DC will also need further standardization. At the moment, the indications are too varied and the procedure is often confounded with secondary DC, especially when the latter is performed early as a neuroprotective procedure ${ }^{61}$ and with decompressive craniotomy. The guidelines from the AANS and the planned randomized studies comparing primary DC and craniotomy are welcome in this regard. However, more needs to be done to define the indications, the procedure, and the outcomes for primary DC.

In severe TBI, two groups of patients must be recognized. First (group A), there are patients with mass lesions and diffuse raised ICP (such as extensive/severe acute traumatic subarachnoid hemorrhage or subdural hematoma) requiring surgery for the cause of their raised ICP. These patients rapidly progress to intractable raised ICP, which becomes medically refractory if surgical intervention is delayed. Second (group B), there are patients without any surgically amenable mass lesions, but with medically intractable raised ICP. A third group may be identified from the literature from centers where ICP is not monitored, and where the severity of ICP is clinically inferred ${ }^{17}$ These include patients from the first two groups, but also patients with mass lesions without significantly raised ICP, or perhaps raised ICP that is not necessarily intractable. DC will be useful in these patients, but a cohort of such patients will benefit from only decompressive craniotomy with the bone allowed to float until the ICP settles. For clarity, the third group of patients should not be classed with patients requiring DC if the efficacy of DC is to be rigorously determined. Patients in group $\mathrm{A}$ are more likely to improve with DC than patients in group B, especially when the surgery is done early. When grouped together, the results of DC become variable and this may have contributed to the lack of clarity in the role of DC in the management of TBI. It is in group B patients that we most urgently need clarity about the role of DC.

Decompressive "craniectomy" and decompressive "craniotomy" have been loosely used interchangeably, but they are not exactly the same. While the DC procedure results in complete detachment of the bone flap from the cranium, the same bone is left floating and still retains its attachment to the muscle and/or soft tissues in decompressive craniotomy procedures. In theory, therefore, the "vent" effect achieved from DC is superior to that of craniotomy, although issues related to the subsequent need for cranioplasty procedures, brain protection, bone infection, and storage facility may make the latter more preferable in developing countries. ${ }^{17}$

Many types of DC procedures have been described in the literature, including circumferential hemicraniectomy, as well as unilateral or bilateral frontal and subtemporal DC.72 It is strongly recommended that an extensive durotomy followed with or without watertight duroplasty be carried out during any decompressive surgery procedure. Duroplasty using autologous material or artificial dura helps to preserve the anatomical plane between the muscle and the brain for ease of cranioplasty. The use of collagen matrix that allows for ingrowth of tissue similar to the dura has been advocated. ${ }^{72}$ Some surgeons, however, believe that following durotomy, watertight duroplasty may not be necessary, especially in clinically unstable patients undergoing decompressive craniotomy, as this leaves room for CSF drainage in the immediate perioperative period, although the risk of meningitis may be higher.

Subtemporal DC was described by Cushing ${ }^{20}$ around the First World War and aims to prevent uncal herniation by creating space for the temporal lobes, thereby relieving compression on the brainstem. It has also been described for the treatment of pseudotumour cerebri. Unilateral hemispheric DC is often performed in trauma, especially if there is an associated structural lesion, like acute subdural hematoma, and a midline shift to the contralateral side. This is also used for MCA stroke. Unlike the conventional craniotomy used for tumor and unruptured aneurysm surgery, the flap dimension is usually in the range of $8-10 \mathrm{~cm} \times 12-15 \mathrm{~cm}$ on the affected side. Although contestable, the bone removal should also be extended as low as possible to ensure temporal lobe decompression, especially if there is already a temporal lobe structural lesion, edema, contusion, or uncal herniation. Some even recommend manual release of the temporal lobe in cases of uncal herniation. ${ }^{73}$

Occasionally, bilateral hemicraniectomy is done, especially in adults with bilateral structural lesions with 
central herniation. In this procedure, only a rim of bone is retained over the superior sagittal sinus to protect it. This is, however, associated with more morbidity, and the challenge of immediate postoperative positioning and management; a viable option is bifrontal DC. Bifrontal DC was described by Kjellberg and Prieto, ${ }^{27}$ and this option has been found to be very useful in the pediatric age group, especially where ICP elevation is the result of only diffuse brain injuries without structural mass lesions. This technique was used in the randomized study of DC in children by Polin et al, ${ }^{74}$ and it was adopted by the DECRA team.

Although there are no absolute contraindications, factors like advancing age, fatal brain injury with irreversible brainstem signs, or herniation with neurological signs, or evidence of ischemic brain damage from evoked potential, as well as ICP monitoring with B wave may be poor surgical candidates.

\section{Cranioplasty}

Cranioplasty has a history almost as old as that of trephination. ${ }^{75}$ Although by definition cranioplasty implies a repair of defects of the skull irrespective of time, its common usage assumes a temporal separation between the creation of the cranial defect and its subsequent repair, or that some material other than the original bone is used for the repair. ${ }^{75}$ In addition to reconstructing the cranial defect, thus providing protection for intracranial contents, cranioplasty provides aesthetic and psychological support for the patient. ${ }^{76}$

Various materials have been used for cranioplasty, ranging from autografts through allografts and xenografts, to nonliving tissues such as metals and other synthetics. ${ }^{75}$ Methyl methacrylate, titanium, and autologous bone are presently the most commonly used materials. The plethora of materials in use is testimony to the fact that no ideal material exists. As suggested by Sanan and Haines, ${ }^{75}$ such ideal material should be strong, malleable, lightweight, thermally nonconductive, easily secured, radiolucent, and nonmagnetic, among other qualities. The use of the patient's own bone, where possible, represents this ideal most nearly. It is cost effective and is an automatic fit, although there may be some degree of resorption from storage. The major problem, however, has been the preservation of autologous bone for subsequent use. This has varied from storage in scalp pockets or abdominal pockets to frozen storage..$^{77,78}$

Among the plethora of materials used, the most common had been polymethylmethacrylate (PMMA) and titanium plates or mesh. ${ }^{75}$ More recently, custom-made cranioplasty has evolved along the lines of using hydroxyapatite, which can allow for osteointegration. PMMA has a long history of use, ${ }^{75,79}$ and it continues to enjoy its preference in developing and poor economy countries because of its costs and malleability in the early stages of preparation before hardening. It could thus be molded to fit the contour of the defect in most cases, and once placed, is relatively biologically inert and radiolucent. A major setback, however, is the thermal reaction during polymerization, which requires exceptional care to avoid tissue damage. Other difficulties include contouring difficulties for some parts of the cranium, particularly the cranial basis and the increased risk of infection. Although expensive, titanium cranioplasty is a viable option because of its magnetic resonance compatibility. First used by Simpson, ${ }^{80}$ it has been argued to give better cosmesis while avoiding the challenge of bone resorption, bone storage, and increased risk of infection associated with autologous bone. It is, however, less malleable and therefore more difficult to shape.

Traditionally, cranioplasty was delayed for 6-12 months following DC to reduce the risk of subsequent infection. ${ }^{81}$ The more recent trend is for early cranioplasty performed after 4-12 weeks, by which time the brain swelling would have improved. ${ }^{82-84}$ Studies have shown that cranioplasty allows for increased perfusion, correlating with neurological improvement, and this is another argument for early cranioplasty. ${ }^{85}$ The timing may, however, be prolonged if there is a complicating brain infection in the postoperative period. Cranioplasty is associated with complication rates up to $34 \%$ in some series, with the majority of these patients requiring further operation. ${ }^{86}$ These complications include infection, wound dehiscence, epidural and subdural hematoma, bone resorption, status epilepticus, hydrocephalus, and deep vein thromboses. Infection has been reported to occur in $10 \%-12 \%$ of patients, depending on the material used. ${ }^{86-88}$ Adhesions between the brain and scalp may be a source of neurological injury during subsequent exposure of the brain for the cranioplasty. ${ }^{89}$

\section{Complications of DC}

DC is associated with its own peculiar complications. In the early phase following decompression, the head is asymmetrically deformed. As swelling resolves, the patient develops depressed concavity that may be profound if associated with secondary brain atrophy. Compromise of temporalis muscle function limits jaw movement.

In the immediate perioperative period, removal of tamponading bone flap may result in the blooming of contusions ${ }^{90}$ and, sometimes, in the development of contralateral acute subdural hematoma, especially in the presence of 
contralateral skull fracture..$^{91,92}$ In Flint's series, as many as $58 \%$ had blossoming of hemorrhagic contusion with up to $80 \%$ of these occurring ipsilateral to the craniectomy. ${ }^{90}$ The volume of the hemorrhagic contusion has been shown to correlate with the outcome.

One of the goals of DC is to achieve external decompression of the intracranial contents, but this can result in compression of the cortical veins and infarctions, especially where the craniectomy size is inadequate. External herniation, measured as brain tissue in the center of the bone defect greater than $1.5 \mathrm{~cm}$ above the plane of the outer table of the cranium, was found to occur in $26 \%$ of 108 craniectomies. ${ }^{91}$ Herniation often occurs in the early postdecompression period and has been thought to be related to progressive swelling of the underlying brain. This may be due to reduced resistance and increased hydrostatic pressure in the brain tissue lacking protective skull. Transcapillary leakage of fluid causing edema in these circumstances has been demonstrated in animal studies, but not in patients with craniectomy. ${ }^{89}$

In the intermediate period, subdural hygromas and infections may be a problem. Subdural hygromas may occur as early as the first week postcraniectomy and are generally ipsilateral. ${ }^{40}$ Frequencies of subdural hygromas as high as $25 \%-60 \%$ have been reported following $\mathrm{DC},{ }^{89,91}$ and are considered to either result from altered CSF dynamics or increased CPP following decompression. ${ }^{93}$ The hygromas tend to resolve spontaneously over weeks to months, ${ }^{40,89,91}$ and there is rarely any need for tapping of the hygroma or lumboperitoneal shunts. Duroplasty at the initial decompression lowers the incidence of hygroma formation. ${ }^{89}$

Infections may complicate DC in the intermediate or late postdecompression period. Factors associated with increased infection include larger scalp incisions, compromise of vascular pedicle to the flap or air sinuses from the large bone flap, and duroplasty using artificial substitutes. ${ }^{89}$ In addition, these patients are managed in the intensive care units where infections are more likely. Cranioplasty increases the risk of infection, especially when repair is done early. The type of material and duration of storage of bone also increase infection rates.

In the delayed phase beyond 1 month, hydrocephalus has been reported in between $10 \%-40 \%$ of patients. ${ }^{4,40,94}$ It seems likely that symptomatic hydrocephalus results from the failure of the altered CSF dynamics that lead to the development of hygromas to normalize. ${ }^{95}$ Treatment of the hydrocephalus is rarely indicated before the replacement of the bone flap. Where indicated, shunt placement should be done after cranioplasty to avoid paradoxical herniation. ${ }^{96}$ In the presence of a large skull defect, CSF loss - as may occur with lumbar puncture - worsens the negative pressure gradient between the atmosphere and the cranium, ${ }^{97}$ and it may result in brain shifts. Although uncommon, paradoxical brain herniation has been described in post-DC patients who undergo lumbar puncture procedures, which may manifest around the time of mobilization for rehabilitation. ${ }^{97}$ In the early period, paradoxical herniation may be mistaken for neurological damage from the original trauma.

The syndrome of the trephined first described by Grant and Norcross ${ }^{98}$ is another common delayed complication that is often underdiagnosed. The syndrome may be related to the direct effect of atmospheric pressure causing closure of the subarachnoid space and impairing brain perfusion. The syndrome is often completely reversed after replacement of the bone flap. Common manifestations include headaches, dizziness, irritability, difficulty with concentration, memory, and mood disturbances. These symptoms are indistinguishable from posthead injury syndrome, and can only be distinguished if cranioplasty results in improvement. Stiver et $\mathrm{al}^{99}$ have described a motor trephine syndrome that also responds to cranioplasty.

The nature of complications associated with DC have an important role to play when making decisions for surgery. Although the surgery of DC is relatively simple, it also has significant potential for adverse outcomes, especially considering the emergency nature of the procedures and the chance that younger neurosurgeons are more likely to undertake the surgery. Complications of DC have been found to be increased with the severity of the injury, advancing age, and patients on aspirin or other anticoagulants. ${ }^{89}$

\section{Conclusion}

The role of DC in trauma is still being debated. While DC can prevent secondary brain injury following TBI, it does not reverse the primary brain injury. The outcome in terms of survival and quality of that survival has been at the center of the debate, and will only be resolved by rigorous definition of the procedure and the criteria for its use. The DECRA study has raised serious contentions, but more randomized studies are necessary and are awaited. A number of factors are known to influence prognosis in TBI managed with DC. Reported outcomes show wide variations from different parts of the world. While reported good outcomes vary from $7 \%-70 \%$, mortality ranges from $13 \%-90 \% .{ }^{18}$ The elderly, especially those more than 60 years old, have worse outcomes, probably because of associated morbidity. Clinically, a low postresuscitation GCS, systolic hypotension and respiratory insufficiency, polytrauma, the absence of brainstem reflexes, bilateral pupil dilation, refractory ICP rise, compromise of 
the basal cisterns, the severity of midline shift, the severity of associated edema, volume of the associated intracerebral hemorrhage, severity of diffuse axonal injury, or acute subdural hematoma are associated with poor outcomes. ${ }^{18}$ Outcomes also depend on the timing of surgery and the GCS score before surgery.

\section{Disclosure}

The authors report no conflicts of interest in this work.

\section{References}

1. Hofmeijer J, Kappelle LJ, Algra A, Amelink GJ, van Gijn J, van der Worp HB; HAMLET investigators. Surgical decompression for space-occupying cerebral infarction (the Hemicraniectomy After Middle Cerebral Artery infarction with Life-threatening Edema Trial [HAMLET]): a multicentre, open, randomised trial. Lancet Neurol. 2009;8(4):326-333.

2. Jüttler E, Schwab S, Schmiedek P, et al; DESTINY Study Group. Decompressive Surgery for the Treatment of Malignant Infarction of the Middle Cerebral Artery (DESTINY): a randomized, controlled trial. Stroke. 2007;38(9):2518-2525.

3. Vahedi K, Hofmeijer J, Juettler E, et al; DECIMAL, DESTINY, and HAMLET investigators. Early decompressive surgery in malignant infarction of the middle cerebral artery: a pooled analysis of three randomised controlled trials. Lancet Neurol. 2007;6(3):215-222.

4. Howard JL, Cipolle MD, Anderson M, et al. Outcome after decompressive craniectomy for the treatment of severe traumatic brain injury. J Trauma. 2008;65(2):380-385.

5. Jagannathan J, Okonkwo DO, Dumont AS, et al. Outcome following decompressive craniectomy in children with severe traumatic brain injury: a 10-year single-center experience with long-term follow up. J Neurosurg. 2007;106(4 Suppl):268-275.

6. Kan P, Amini A, Hansen K, et al. Outcomes after decompressive craniectomy for severe traumatic brain injury in children. J Neurosurg. 2006;105(5 Suppl):337-342.

7. Albanèse J, Leone M, Alliez JR, et al. Decompressive craniectomy for severe traumatic brain injury: Evaluation of the effects at one year. Crit Care Med. 2003;31(10):2535-2538.

8. Jiang JY, Xu W, Li WP, et al. Efficacy of standard trauma craniectomy for refractory intracranial hypertension with severe traumatic brain injury: a multicenter, prospective, randomized controlled study. $J$ Neurotrauma. 2005;22(6):623-628.

9. Chesnut RM, Temkin N, Carney N, et al; Global Neurotrauma Research Group. A trial of intracranial-pressure monitoring in traumatic brain injury. $N$ Engl J Med. 2012;367(26):2471-2481.

10. Bullock MR, Povlishock JT. Guidelines for the management of severe traumatic brain injury. Editor's commentary. J Neurotrauma. 2007; 24 Suppl 1:2 p preceding S1.

11. Kolias AG, Kirkpatrick PJ, Hutchinson PJ. Decompressive craniectomy: past, present and future. Nat Rev Neurol. 2013;9(7):405-415.

12. Farahvar A, Gerber LM, Chiu YL, et al. Response to intracranial hypertension treatment as a predictor of death in patients with severe traumatic brain injury. J Neurosurg. 2011;114(5):1471-1478.

13. Balestreri M, Czosnyka M, Hutchinson P, et al. Impact of intracranial pressure and cerebral perfusion pressure on severe disability and mortality after head injury. Neurocrit Care. 2006;4(1):8-13.

14. Cooper DJ, Rosenfeld JV, Murray L, et al; DECRA Trial Investigators; Australian and New Zealand Intensive Care Society Clinical Trials Group. Decompressive craniectomy in diffuse traumatic brain injury. N Engl J Med. 2011;364(16):1493-1502.

15. Randomised Evaluation of Surgery with Craniectomy for Uncontrolled Elevation of ICP [homepage on the Internet]. Available from: www. rescueicp.com.
16. Haddad SH, ArabiYM. Critical care management of severe traumatic brain injury in adults. Scand J Trauma Resusc Emerg Med. 2012;20:12.

17. Mezue WC, Ndubuisi C, Ohaegbulam SC, Chikani M, Erechukwu U. Cranial bony decompressions in the management of head injuries: decompressive craniotomy or craniectomy? Niger J Clin Pract. 2013; 16(3):343-347.

18. Wani AA, Dar TI, Ramzan AU, et al. Decompressive craniectomy in head injury. The Indian Journal of Neurotrauma. 2009;6(2):103-110.

19. Kocher T. Die therapiedes Hirndruck und chirurgische Eangriffe bei Hirnkrankhete. Vienna: A Holder; 1901.

20. Cushing H. I. Subtemporal decompressive operations for the intracranial complications associated with bursting fractures of the skull. Ann Surg. 1908;47(5):641-644. 1.

21. Lewin W, Marshall TF, Roberts AH. Long-term outcome after severe head injury. Br Med J. 1979;2(6204):1533-1538.

22. Moody RA, Ruamsuke S, Mullan SF. An evaluation of decompression in experimental head injury. J Neurosurg. 1968;29(6):586-590.

23. Guerra WK, Gaab MR, Dietz H, Mueller JU, Piek J, Fritsch MJ. Surgical decompression for traumatic brain swelling: indications and results. J Neurosurg. 1999;90(2):187-196.

24. Wilberger JE, Harris M, Diamond DL. Acute subdural hematoma: morbidity, mortality, and operative timing. J Neurosurg. 1991;74(2):212-218.

25. Sahuquillo J, Arikan F. Decompressive craniectomy for the treatment of refractory high intracranial pressure in traumatic brain injury. Cochrane Database Syst Rev. 2006;(1):CD003983.

26. Taylor A, Butt W, Rosenfeld J, et al. A randomized trial of very early decompressive craniectomy in children with traumatic brain injury and sustained intracranial hypertension. Childs Nerv Syst. 2001;17(3):154-162.

27. Kjellberg RN, Prieto A. Bifrontal decompressive craniotomy for massive cerebral edema. J Neurosurg. 1971;34(4):488-493.

28. Finkelstein EA, Corso PS, Miller TR. Incidence and Economic Burden of Injuries in the United States. New York, NY: Oxford University Press; 2006.

29. Faul M, Wald MM, Rutland-Brown W, Sullivent EE, Sattin RW. Using a cost-benefit analysis to estimate outcomes of a clinical treatment guideline: testing the Brain Trauma Foundation guidelines for the treatment of severe traumatic brain injury. J Trauma. 2007;63(6): 1271-1278.

30. Access Economics Pty Limited for the Victorian Neurotrauma Initiative. The Economic Cost of Spinal Cord Injury and Traumatic Brain Injury in Australia. Sydney, Australia: Access Economics Pty Limited; 2009. Available from: http://www.tac.vic.gov.au/about-the-tac/our-organisation/research/tac-neurotrauma-research/vni/the20economic20cost20o f20spinal20 cord20injury20and20traumatic20brain20injury20in20australia.pdf. Accessed February 8, 2015.

31. Gouello G, Hamel O, Asehnoune K, Bord E, Robert R, Buffenoir K. Study of the long-term results of decompressive craniectomy after severe traumatic brain injury based on a series of 60 consecutive cases. Scientific World Journal. 2014;2014:207585.

32. Schwab S, Aschoff A, Spranger M, Albert F, Hacke W. The value of intracranial pressure monitoring in acute hemispheric stroke. Neurology. 1996;47(2):393-398.

33. Balan C, Alliez B. Decompressive craniectomy - from option to standard - part I. Romanian Neurosurgery. 2009;16(2):20-26.

34. Patel N, West M, Wurster J, Tillman C. Pediatric traumatic brain injuries treated with decompressive craniectomy. Surg Neurol Int. 2013;4:128.

35. Patel HC, Menon DK, Tebbs S, Hawker R, Hutchinson PJ, Kirkpatrick PJ. Specialist neurocritical care and outcome from head injury. Intensive Care Med. 2002;28(5):547-553.

36. Fakhry SM, Trask AL, Waller MA, Watts DD; IRTC Neurotrauma Task Force. Management of brain-injured patients by an evidence-based medicine protocol improves outcomes and decreases hospital charges. J Trauma. 2004;56(3):492-499; discussion 499-500.

37. Fuller G, Bouamra O, Woodford M, et al. The effect of specialist neurosciences care on outcome in adult severe head injury: a cohort study. J Neurosurg Anesthesiol. 2011;23(3):198-205. 
38. Eisenberg HM, Frankowski RF, Contant CF, Marshall LF, Walker MD. High-dose barbiturate control of elevated intracranial pressure in patients with severe head injury. J Neurosurg. 1988;69(1):15-23.

39. Howells T, Elf K, Jones PA, et al. Pressure reactivity as a guide in the treatment of cerebral perfusion pressure in patients with brain trauma. J Neurosurg. 2005;102(2):311-317.

40. Aarabi B, Hesdorffer DC, Ahn ES, Aresco C, Scalea TM, Eisenberg HM. Outcome following decompressive craniectomy for malignant swelling due to severe head injury. J Neurosurg. 2006;104(4):469-479.

41. Timofeev I, Kirkpatrick PJ, Corteen E, et al. Decompressive craniectomy in traumatic brain injury: outcome following protocol-driven therapy. Acta Neurochir Suppl. 2006;96:11-16.

42. Mauritz W, Steltzer H, Bauer P, Dolanski-Aghamanoukjan L, Metnitz P. Monitoring of intracranial pressure in patients with severe traumatic brain injury: an Austrian prospective multicenter study. Intensive Care Med. 2008;34(7):1208-1215.

43. Stocchetti N, Penny KI, Dearden M, et al; European Brain Injury Consortium. Intensive care management of head-injured patients in Europe: a survey from the European brain injury consortium. Intensive Care Med. 2001;27(2):400-406.

44. Cremer OL, van Dijk GW, van Wensen E, et al. Effect of intracranial pressure monitoring and targeted intensive care on functional outcome after severe head injury. Crit Care Med. 2005;33(10):2207-2213.

45. Cremer OL. Does ICP monitoring make a difference in neurocritical care? Eur J Anaesthesiol Suppl. 2008;42:87-93.

46. Shafi S, Diaz-Arrastia R, Madden C, Gentilello L. Intracranial pressure monitoring in brain-injured patients is associated with worsening of survival. J Trauma. 2008;64(2):335-340.

47. Haddad S, Aldawood AS, Alferayan A, Russell NA, Tamim HM, Arabi YM. Relationship between intracranial pressure monitoring and outcomes in severe traumatic brain injury patients. Anaesth Intensive Care. 2011;39(6):1043-1050.

48. Treggiari MM, Schutz N, Yanez ND, Romand JA. Role of intracranial pressure values and patterns in predicting outcome in traumatic brain injury: a systematic review. Neurocrit Care. 2007;6(2):104-112.

49. Chambers IR, Treadwell L, Mendelow AD. Determination of threshold levels of cerebral perfusion pressure and intracranial pressure in severe head injury by using receiver-operating characteristic curves: an observational study in 291 patients. J Neurosurg. 2001;94(3): 412-416.

50. Badri S, Chen J, Barber J, et al. Mortality and long-term functional outcome associated with intracranial pressure after traumatic brain injury. Intensive Care Med. 2012;38(11):1800-1809.

51. Servadei F. Clinical value of decompressive craniectomy. N Engl J Med. 2011;364(16):1558-1559.

52. Simard JM, Kahle KT, Walcott BP. Craniectomy in diffuse traumatic brain injury. $N$ Engl J Med. 2011;365(4):374; author reply 376.

53. Hutchinson PJ, Kirkpatrick PJ; RESCUEicp Central Study Team. Craniectomy in diffuse traumatic brain injury. $N$ Engl J Med. 2011; 365(4):375; author reply 376 .

54. Clifton GL, Miller ER, Choi SC, et al. Lack of effect of induction of hypothermia after acute brain injury. $N$ Engl J Med. 2001;344(8):556-563.

55. Roberts I. Barbiturates for acute traumatic brain injury. Cochrane Database Syst Rev. 2000;(2):CD000033.

56. Stiefel MF, Udoetuk JD, Spiotta AM, et al. Conventional neurocritical care and cerebral oxygenation after traumatic brain injury. J Neurosurg. 2006;105(4):568-575.

57. Maloney-Wilensky E, Gracias V, Itkin A, et al. Brain tissue oxygen and outcome after severe traumatic brain injury: a systematic review. Crit Care Med. 2009;37(6):2057-2063.

58. Coles JP, Minhas PS, Fryer TD, et al. Effect of hyperventilation on cerebral blood flow in traumatic head injury: clinical relevance and monitoring correlates. Crit Care Med. 2002;30(9):1950-1959.

59. Hautefeuille S, Francony G, Payen JF. Craniectomy in diffuse traumatic brain injury. N Engl J Med. 2011;365(4):374-375; author reply 376.

60. Chen SH, Chen Y, Fang WK, Huang DW, Huang KC, Tseng SH. Comparison of craniotomy and decompressive craniectomy in severely head-injured patients with acute subdural hematoma. JTrauma. 2011; 71(6):1632-1636.
61. Weiner GM, Lacey MR, Mackenzie L, et al. Decompressive craniectomy for elevated intracranial pressure and its effect on the cumulative ischemic burden and therapeutic intensity levels after severe traumatic brain injury. Neurosurgery. 2010;66(6):1111-1118; discussion 1118-1119.

62. Whitfield PC, Patel H, Hutchinson PJ, et al. Bifrontal decompressive craniectomy in the management of posttraumatic intracranial hypertension. Br J Neurosurg. 2001;15(6):500-507.

63. Cooper DJ, Rosenfeld JV, Murray L, et al. Early decompressive craniectomy for patients with severe traumatic brain injury and refractory intracranial hypertension - a pilot randomized trial. J Crit Care. 2008;23(3):387-393.

64. Hutchinson PJ, Timofeev I, Kolias AG, et al. Decompressive craniectomy for traumatic brain injury: the jury is still out. $\mathrm{Br} J$ Neurosurg. 2011;25(3):441-442.

65. Compagnone C, Murray GD, Teasdale GM, et al; European Brain Injury Consortium. The management of patients with intradural posttraumatic mass lesions: a multicenter survey of current approaches to surgical management in 729 patients coordinated by the European Brain Injury Consortium. Neurosurgery. 2005;57(6):1183-1192; discussion 1183-1192.

66. Coplin WM, Cullen NK, Policherla PN, et al. Safety and feasibility of craniectomy with duraplasty as the initial surgical intervention for severe traumatic brain injury. J Trauma. 2001;50(6):1050-1059.

67. Bullock MR, Chesnut R, Ghajar J, et al; Surgical Management of Traumatic Brain Injury Author Group. Surgical management of acute subdural hematomas. Neurosurgery. 2006;58(3 Suppl):S16-S24; discussion Si-Siv.

68. Kolias AG, Belli A, Li LM, et al. Primary decompressive craniectomy for acute subdural haematomas: results of an international survey. Acta Neurochir (Wien). 2012;154(9):1563-1565.

69. Li LM, Kolias AG, Guilfoyle MR, et al. Outcome following evacuation of acute subdural haematomas: a comparison of craniotomy with decompressive craniectomy. Acta Neurochir (Wien). 2012;154(9):1555-1561.

70. Kolias AG, Scotton WJ, Belli A, et al; UK Neurosurgical Research Network; RESCUE-ASDH collaborative group. Surgical management of acute subdural haematomas: current practice patterns in the United Kingdom and the Republic of Ireland. Br J Neurosurg. 2013;27(3):330-333.

71. Elwatidy S. Bifrontal decompressive craniotomy for malignant brain edema. Saudi Med J. 2006;27(10):1547-1553.

72. Horaczek JA, Zierski J, Graewe A. Collagen matrix in decompressive hemicraniectomy. Neurosurgery. 2008;63(1 Suppl 1): ONS176-ONS181.

73. Huang X, Wen L. Technical considerations in decompressive craniectomy in the treatment of traumatic brain injury. Int J Med Sci. 2010;7(6): 385-390.

74. Polin RS, Shaffrey ME, Bogaev CA, et al. Decompressive bifrontal craniectomy in the treatment of severe refractory posttraumatic cerebral edema. Neurosurgery. 1997;41(1):84-92; discussion 92-94.

75. Sanan A, Haines SJ. Repairing holes in the head: a history of cranioplasty. Neurosurgery. 1997;40(3):588-603.

76. Baldo S, Tacconi L. Effectiveness and safety of subcutaneous abdominal preservation of autologous bone flap after decompressive craniectomy: a prospective pilot study. World Neurosurg. 2010;73(5):552-556.

77. Mezue WC, O'Reilly G, Ohaegbulam SC. The utility of storage of bone flaps in anterior abdominal wall pockets following decompressive craniectomies for severe traumatic brain injuries. Port Harcourt Medical Journal. 2012;6(2):204-210.

78. Mezue WC, Erechukwu AU, Ndubuisi C, Ohaegbulam SC, Chikani MC. Severe traumatic brain injury managed with decompressive craniectomy. Niger J Clin Pract. 2012;15(3):369-371.

79. van Gool AV. Preformed polymethylmethacrylate cranioplasties: report of 45 cases. J Maxillofac Surg. 1985;13(1):2-8.

80. Simpson D. Titanium in cranioplasty. J Neurosurg. 1965;22:292-293.

81. Rish BL, Dillon JD, Meirowsky AM, et al. Cranioplasty: a review of 1030 cases of penetrating head injury. Neurosurgery. 1979;4(5):381-385.

82. Liang W, Xiaofeng Y, Weiguo L, et al. Cranioplasty of large cranial defect at an early stage after decompressive craniectomy performed for severe head trauma. J Craniofac Surg. 2007;18(3):526-532. 
83. Beauchamp KM, Kashuk J, Moore EE, et al. Cranioplasty after postinjury decompressive craniectomy: is timing of the essence? J Trauma. 2010;69(2):270-274.

84. Chun HJ, Yi HJ. Efficacy and safety of early cranioplasty, at least within 1 month. J Craniofac Surg. 2011;22(1):203-207.

85. Maekawa M, Awaya S, Teramoto A. [Cerebral blood flow (CBF) before and after cranioplasty performed during the chronic stage after decompressive craniectomy evaluated by xenon-enhanced computerized tomography (Xe-CT) CBF scanning]. No Shinkei Geka. 1999;27(8):717-722. Japanese.

86. Gooch MR, Gin GE, Kenning TJ, German JW. Complications of cranioplasty following decompressive craniectomy: analysis of 62 cases. Neurosurg Focus. 2009;26(6):E9.

87. Cheng YK, Weng HH, Yang JT, Lee MH, Wang TC, Chang CN. Factors affecting graft infection after cranioplasty. $J$ Clin Neurosci. 2008;15(10):1115-1119.

88. Matsuno A, Tanaka H, Iwamuro H, et al. Analyses of the factors influencing bone graft infection after delayed cranioplasty. Acta Neurochir (Wien). 2006;148(5):535-540; discussion 540.

89. Stiver SI. Complications of decompressive craniectomy for traumatic brain injury. Neurosurg Focus. 2009;26(6):E7.

90. Flint AC, Manley GT, Gean AD, Hemphill JC, Rosenthal G. Post-operative expansion of hemorrhagic contusions after unilateral decompressive hemicraniectomy in severe traumatic brain injury. J Neurotrauma. 2008;25(5):503-512.

91. Yang XF, Wen L, Shen F, et al. Surgical complications secondary to decompressive craniectomy in patients with a head injury: a series of 108 consecutive cases. Acta Neurochir (Wien). 2008;150(12) 1241-1247; discussion 1248 .
92. Su TM, Lee TH, Chen WF, Lee TC, Cheng CH. Contralateral acute epidural hematoma after decompressive surgery of acute subdural hematoma: clinical features and outcome. J Trauma. 2008;65(6): 1298-1302.

93. Lang JK, Ludwig HC, Mursch K, Zimmerer B, Markakis E. Elevated cerebral perfusion pressure and low colloid osmotic pressure as a risk factor for subdural space-occupying hygromas? Surg Neurol. 1999;52(6):630-637.

94. Morgalla MH, Will BE, Roser F, Tatagiba M. Do long-term results justify decompressive craniectomy after severe traumatic brain injury? J Neurosurg. 2008;109(4):685-690.

95. Honeybul S, Ho KM. Long-term complications of decompressive craniectomy for head injury. J Neurotrauma. 2011;28(6):929-935.

96. Liao CC, Kao MC. Cranioplasty for patients with severe depressed skull bone defect after cerebrospinal fluid shunting. J Clin Neurosci. 2002;9(5):553-555.

97. Vilela MD. Delayed paradoxical herniation after a decompressive craniectomy: case report. Surg Neurol. 2008;69(3):293-296; discussion 296.

98. Grant FC, Norcross NC. Repair of cranial defects by cranioplasty. Ann Surg. 1939;110(4):488-512.

99. Stiver SI, Wintermark M, Manley GT. Reversible monoparesis following decompressive hemicraniectomy for traumatic brain injury. J Neurosurg. 2008;109(2):245-254.
Open Access Surgery

\section{Publish your work in this journal}

Open Access Surgery is an international, peer-reviewed, open access journal that focuses on all aspects of surgical procedures and interventions. Patient care around the peri-operative period and patient outcomes post surgery are key topics. All grades of surgery from minor cosmetic interventions to major surgical procedures are covered. Novel techniques

\section{Dovepress}

and the utilization of new instruments and materials, including implants and prostheses that optimize outcomes constitute major areas of interest. The manuscript management system is completely online and includes a very quick and fair peer-review system. Visit http://www.dovepress.com/ testimonials.php to read real quotes from published authors. 